\title{
Study on the Influence of Ecological Ideas on Product Identity Design in Internet age
}

\author{
Shanwei Zhang ${ }^{1, a^{*}}$ and Xufeng Cheng ${ }^{2, b}$ \\ a849006425@qq.com b1141513971@qq.com
}

Keyword: Internet age; Ecological concept; Product identify design; Industrial design

\begin{abstract}
In the background of the internet age, industrial design has been the important driving force of Chinese economic transformation and development. On the basis of meeting the functional requirements, product design is supposed to pay more attention to people-oriented and environment-friendly. Products which are pleasant, livable and sustainable will be more competitive in the market, but also be more representative of the future development trend. Using the rise of the ecological design concept in recent years to guide the product design meets the background of times, study on the relevant design theory and design methods meets the needs of the times. Based on the background of the Internet and the influence of ecological concept on the design of PI (product identify), this paper analyzes and compares the existing PI design content and discusses a new PI design concept which is more in line with the current design concept and future development trend.
\end{abstract}

\section{Introduction}

With the development of the times, the needs of the community, many products have been gradually integrated into the Internet circle. No longer just focus on their own environmental protection or not, but also begin to product itself with other products to form an ecological circle, and put the concept of interaction into the ecological concept. At the same time, these make new demands for product image recognition (PI) design. Whether these effects and changes can form a new design concept that is more in line with the current design concept and future development trend, and to guide product development and industrial upgrading is the purpose of this research exploration and practice.

\section{The Background and Current Situation of Internet Age and Ecological Concept}

Internetera Characteristics of the Study --- "Internet of Things, Intelligent (home), Things and Things". From 2011 Baidu founder Yanhong Li proposed Internet thinking, to March 5, 2015 Premier Keqiang Li in the Twelfth National People's Congress three times in the "Internet + " action plan, indicating that contemporary China into the Internet era such a historical stage, this is a world trend, and the Internet era of human life, production and productivity development has a great role in promoting. In the Internet age, a new production relationship and pattern is being shaped. In this process, the product design concept, production methods will be re-match the new era of social production environment to meet the development requirements of the times.

The Internet era of product construction based on the "Internet + products", the product is no longer independent, but through (mobile) Internet, large data and cloud computing and other data terminals linked to the software and hardware interconnection between the virtual and the connection between the software and software to achieve the hardware and hardware between the interrelated. This design reflects the composition of the Internet "to connect all" design concept. In addition, based on Internet thinking with a user-centered core concept [1].

The Internet era "public entrepreneurship, innovation", grasp the characteristics of the times, conform to the social development trend, enterprises can be recognized and succeeded: Gree, Huawei and other technology-intensive high-tech enterprises due to independent innovation and gradually become a world-renowned enterprise. As the representative of the rapid rise of Internet 
companies, and put forward the concept of product ecology, advocate new domestic goods, concerned about the user experience, so as to establish brand self-confidence and reputation [2-3].

Ecological Design Concept Study --- "Pleasant, Livable, Sustainable". In the information technology revolution and the wave of global economic globalization continues to develop today, by the industrial society has brought such as population expansion, resource depletion, environmental degradation of the ecological crisis. Therefore, with the "energy problem", "ecological problem", "environmental problem" put forward, the global awareness of human society, ecological awareness and environmental protection awareness is rising, the relationship between mankind and nature has entered the fourth stage --- Harmony between man and nature. Thus, the 21 st century is the transition from "black civilization" to "ecological civilization". The ecological culture will replace traditional culture and enter into the field of material life, social life and spiritual life. Human beings overcome the ecological crisis, social crisis and spiritual crisis , To achieve the sustainable development of human society and create an era of ecological civilization [4].

As a modern design concept, design theory and design method, the ecological design concept is the development and perfection of the research technology. At present, some domestic universities and research institutes in the national science and technology, the National Natural Science Foundation and the support of the relevant departments of green manufacturing technology for a wide range of research and exploration, has formed a green manufacturing technology research in the professional team. In recent years, in the promotion of Lu Yongxiang academician set up a green design promotion, Tianjin set up a green design and research institutions and other organizations, are vigorously advocate green design, and actively build a good platform to promote the transformation of related technology achievements, the formation of green Industry [5].

Design education has been adhering to humanistic care, pay attention to people - machine - the environment harmonious symbiosis, advocate green design, Mr. Liu Guanzhong as China's industrial design education leader, has always advocated the designer to have a conscience, the design community should have a conscience, product development to follow Moderate principle, not blind follow, do not follow suit.

(Green) design and the Internet (intelligent) product design as a new thing, from the state to the local, from the industry to the education sector, from the government to the individual, the big environment and the atmosphere are concerned about the ecological environment and the Internet characteristics of the times, Is the design industry on the background and external changes in the environment to make a positive response, but the combination of the two research in the design theory has not yet follow up in time, the lack of theoretical support will affect the design talent training, resulting in design education can not meet Business needs, impact on corporate planning and the future development of the national economy.

\section{Research on the Development and Present Situation of Product Identify (PI) Design}

About Product Identification (PI) Design. Product identification (PI) is the product of a sense of belonging and family sense, corporate culture to get a sense of identity, the formation of product differentiation, one of the effective design means. In the increasingly homogeneous products, the market is very competitive today, to product design as the core of product identification is an important strategic resource competition [6]. Throughout the history of the design, the 1970s Mercedes-Benz cars, BMW cars, Braun Electric and other world famous brand product style formation, and 80 years of Japanese product image concept, are closely related with product identification design. The prototype of the product identification design theory was first proposed by the German designer in the 1970s and first promoted by the German designer in the 1950s at the earliest of the 1950s. Abroad, the current concept of PI in the concept of Product Family: its basis is the cost savings, it is a limited condition, to improve the commercial means of product categories, the main means is to re-use the same technology and technology [7-8 ]. 


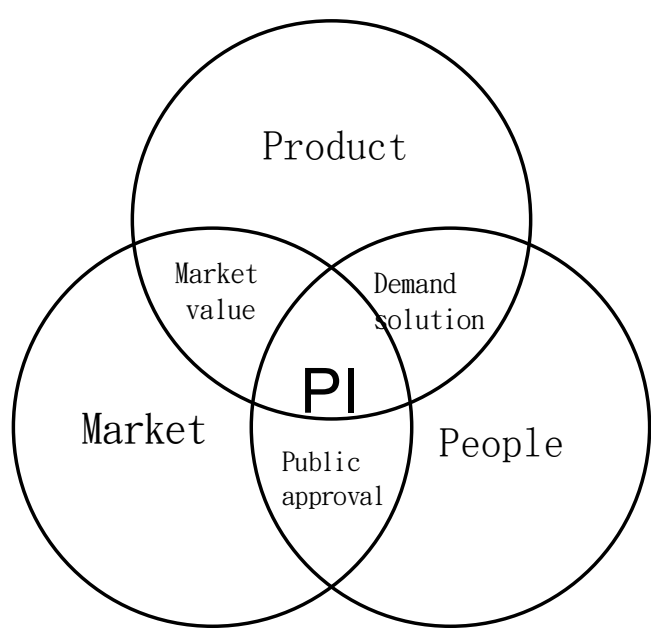

Figure 1. Product, market, human relationship (picture drawn by the author)

Product Identification (PI) Design Status. First of all, PI design concept is through industry, research, product analysis, interview questionnaire to fully understand the enterprise competition. Opponents, design trends, brand value and thus derived. As shown in Figure 2.

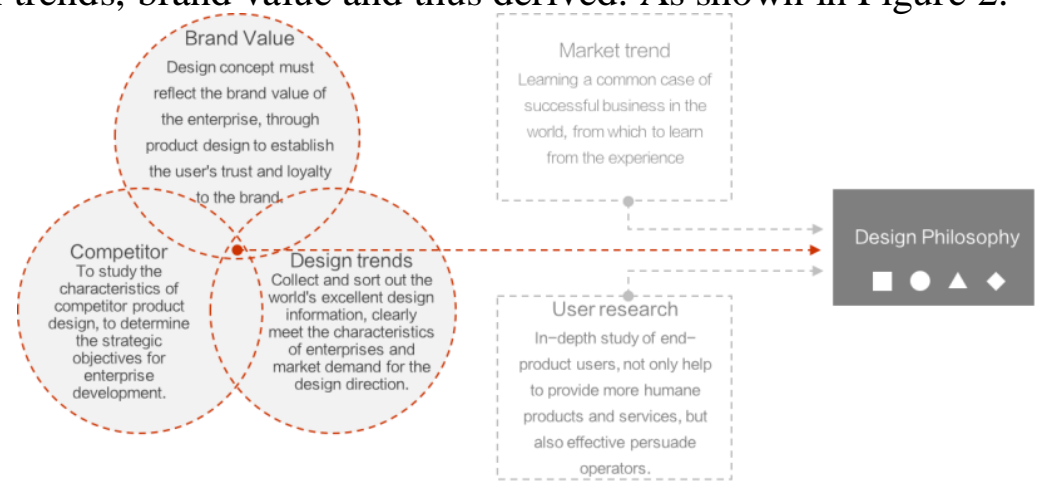

Figure 2. PI design concept source (picture drawn by the author)

Design concept is a clear and simple, people can understand the abstract concept, composed of a number of keywords, reflecting the corporate philosophy and culture, in line with market demand, to guide the aesthetic design of the product. As shown in Figure 3.

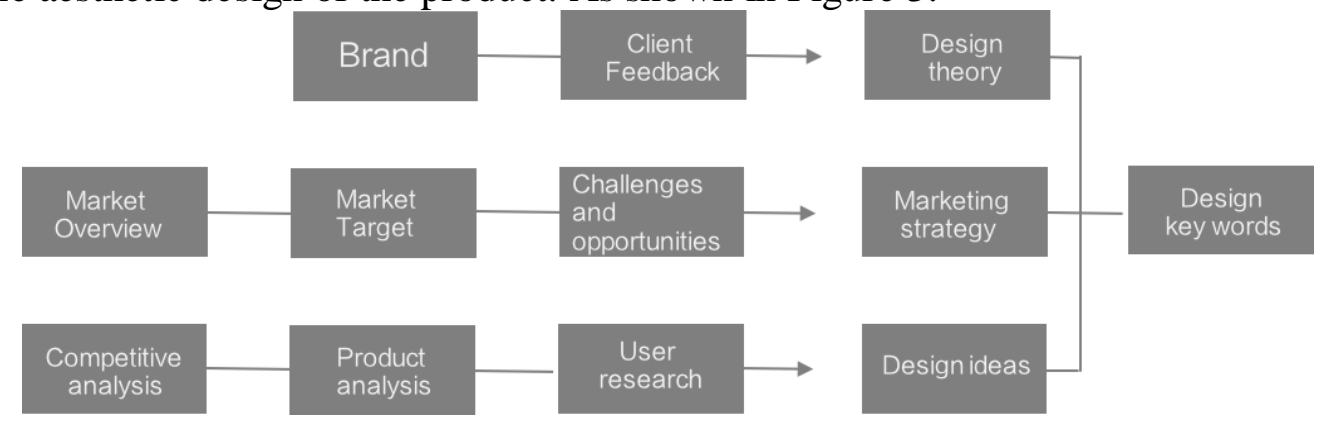

Figure 3 . PI design concept interpretation (picture drawn by the author)

Next, the basic elements of PI are listed. The basic elements of the design to the image of the legend and detailed description of the specific product design, clear in the product design choice between the scope and market positioning differences, including the design elements and man-machine interface specifications [10]. As shown in Figure 4. 


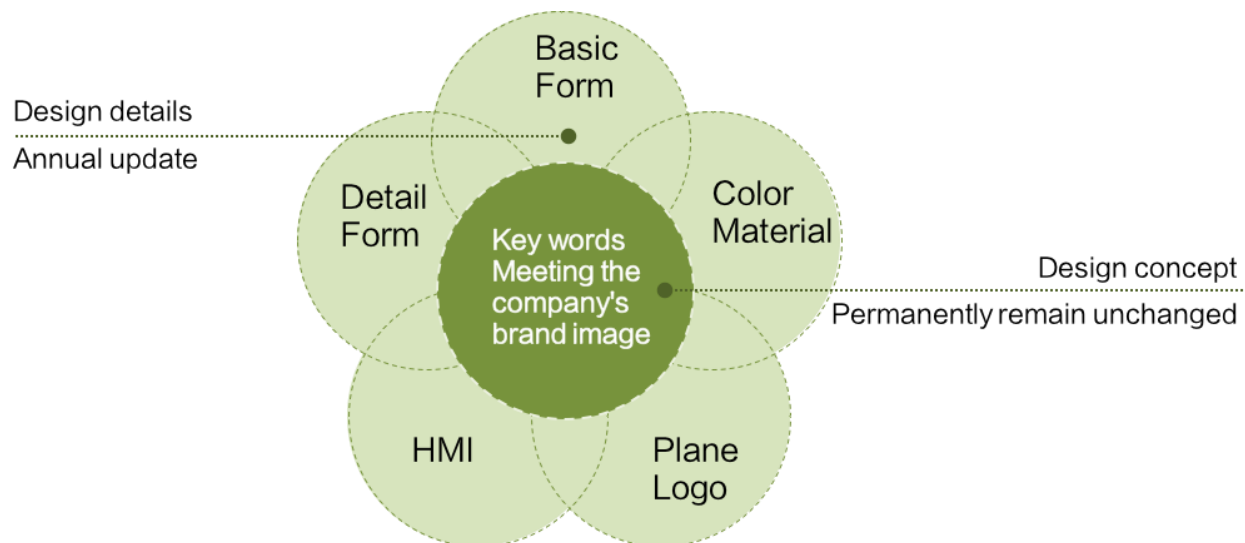

Figure 4. PI design of the basic elements (pictures drawn by the author)

From the conceptual material mentioned earlier, the existing PI design elements include the basic aspects of product modeling, color, material, human-computer interaction, etc., through these elements to carry out PI design, making Products with more of their own characteristics, the formation of serialization. Moreover, the existing PI design has been more mature, design concepts, design methods, design processes have been used for many years, the product itself, the design process or design method is perfect, to say that environmental protection, human. The existing PI design in the material, human-computer interaction in these areas are also reflected, but only for the product itself, the use of environmentally friendly materials, the product and the friendly interaction between users.

Under the influence of the Internet age and ecological concept, the existing PI design gradually began to lack some elements of convergence with the times. A product should not only consider the environmental nature of their own materials, but also should be considered whether the use of the period after the re-use, with new vitality, the formation of a reasonable ecological circle; should not only consider the interaction between users. Should also be the interaction between other products, that is, "things and things" link. For example, these years familiar "smart home" concept, the home electrical products networking, into a virtual circle, and there is a total control side. When you enter the house, the lights, curtains automatically open, the air purifier began to operate, you can also from the phone on the total control end APP to see the home air purification efficiency, air quality and other basic index.

Not long ago done a "coal to electricity" project, this project is to "Beijing part of the coal heating to electricity heating area" to design a record power, control of heating equipment products. In order to reduce the pollution of coal combustion, instead of electricity heating, which is affected by the ecological concept. In order to facilitate the power sector to monitor the use of heating power, home need to install a can upload power, and can remotely control the heating equipment to prevent accidents occur, which is affected by the Internet era. The design of this product is not only from the existing PI design concept required modeling, material, color and other aspects of the basis, but also by the Internet features, ecological ideas affected. In summary, the ecological concept as a guiding ideology is viable, in the Internet era will have a new perspective to give its richer content, and PI design as the concept of the industrial era, to the Internet era will also conform to the times Development needs to upgrade to form a new PI design concept, and guide the design of industrial products towards a pleasant, livable, sustainable direction, enhance people's quality of life, promote social development.

\section{Analysis of cases}

Many companies have followed the trend of the Internet era, the Internet features as their own product design new features, many other industries have also been integrated into the Internet circle. However, not all products with the Internet can have a lasting development. 
Sharing Bicycles. The concept of "sharing bicycles" has now been warming up in the context of the Internet and reaching a state of boiling. According to the author observation and collection of information obtained, at the present, ofo shared bicycles, that is, "yellow car" accounted for the highest market ratio, followed by the motorcycles, and then some of the other shared bicycles. Why is the shared bicycle on the fire? This is inseparable from the current Internet age background. The shared bike is really a bike that is about to be forgotten, and once again pushed to a new heat, mainly because it puts the bike in an internet. We only need to download an app, as shown in Figure 5 , is the use of of shared bicycle bac interface, or direct use of Wechat, you can find the nearby idle shared bicycle, from home or from the school to the subway station, walking Past too far, a taxi in the past even the number of starting kilometers are not enough, this is an embarrassing distance, this time, with a ride anytime, anywhere can ride a bike, it is a good solution to this problem.

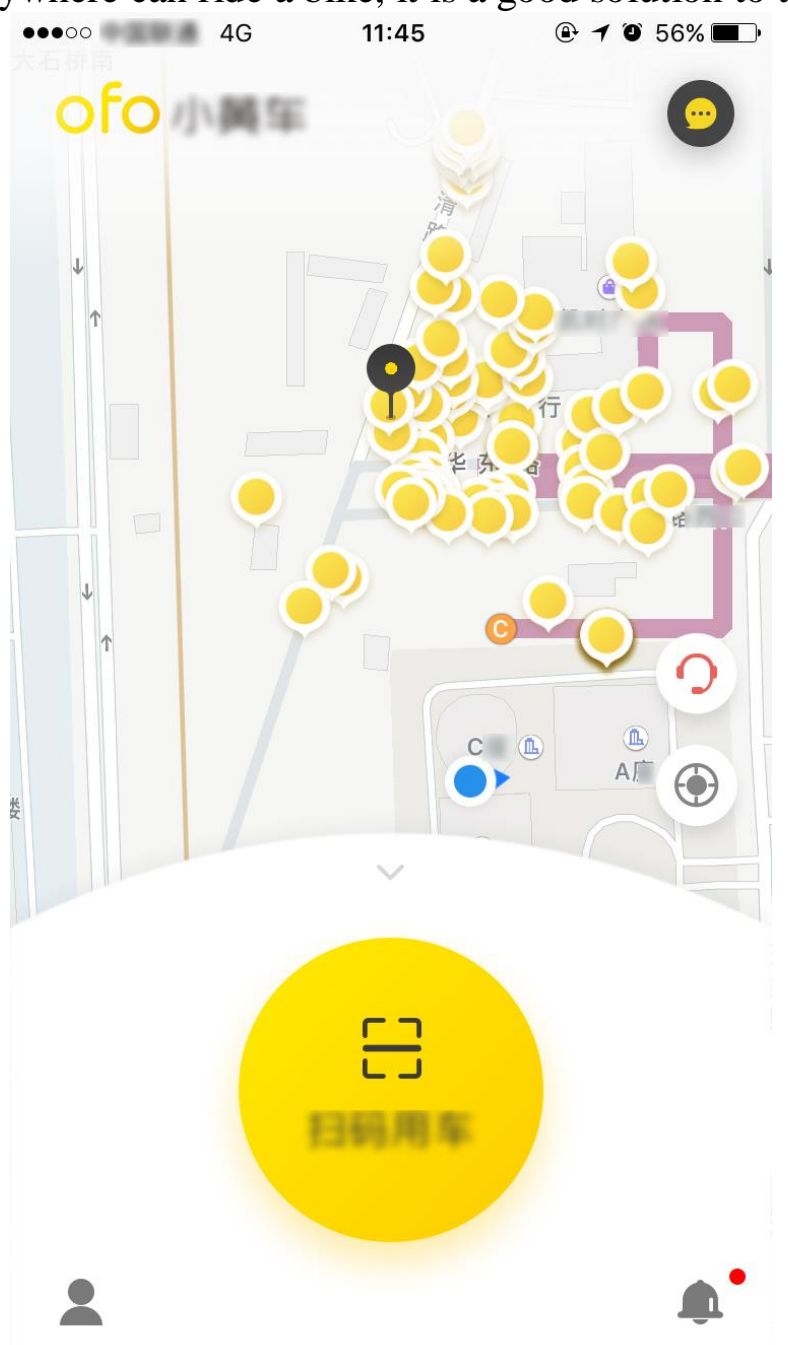

Figure 5. Ofo sharing bicycle app (picture from the network)

And share the banner is also under the banner of environmental protection, reduce car travel, riding more, less exhaust emissions, damage to the environment, but also the way to exercise the body. It seems that all this is a good presence, the Internet and ecological ideas, so that the bike to get a new life, so that people's lives more convenient, so that the air can be more fresh. However, with the use of shared cycling time, some problems can not be ignored also emerged. Walking on the road, you can often see the scene as shown in Figure 6, broken heavy yellow car, no tread, or no wheels, no seat. Ofo sharing bicycles, although accounting for most of the market, but the bicycle damage rate is very high, according to the side often use the yellow car feedback, and now the yellow car scrap rate is extremely high, often encountered broken yellow car, unlock Before you have to carefully check whether there is damage, dare to feel relieved to unlock and use. 


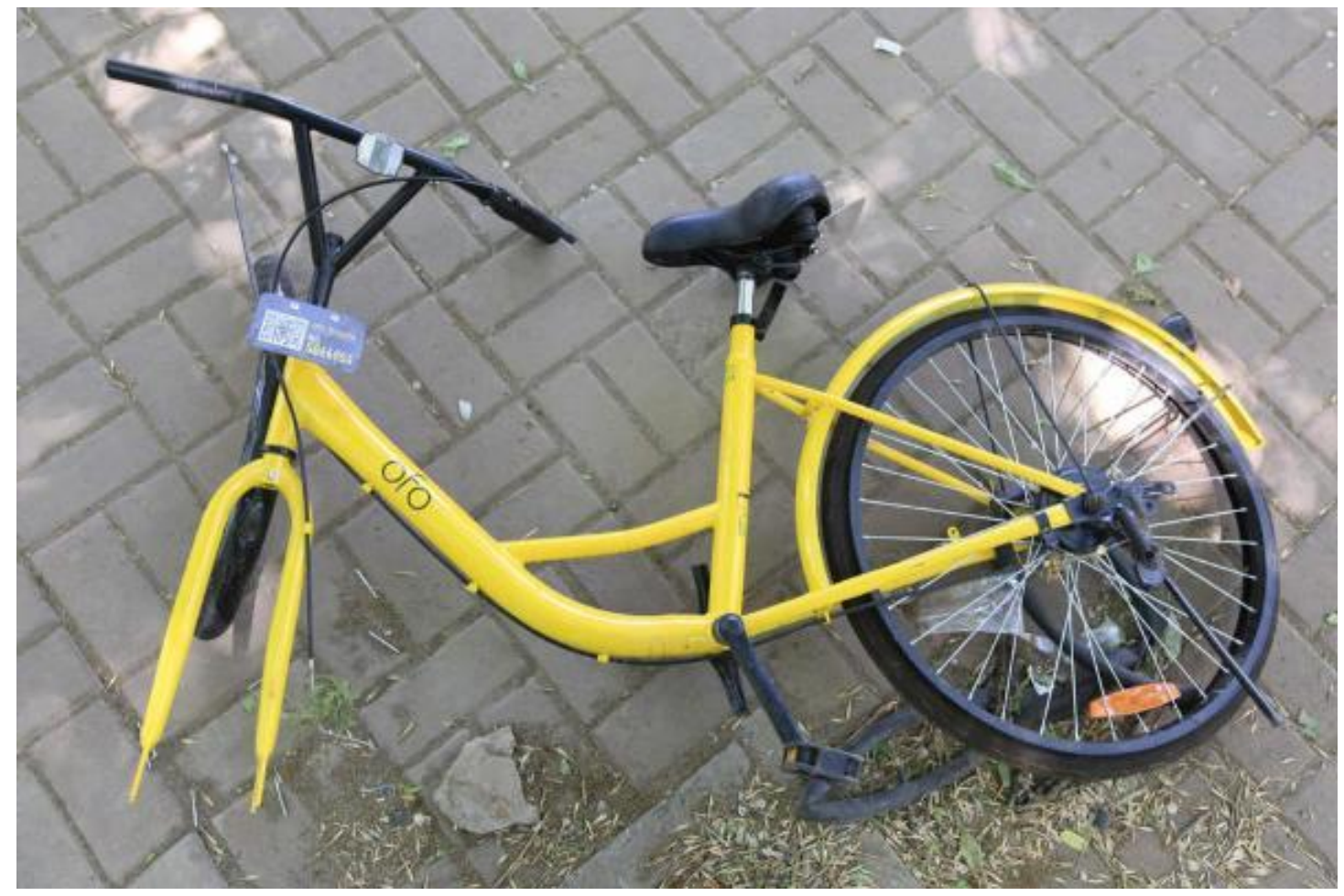

Figure 6. Destroyed ofo shared bikes (pictures from the network)

This phenomenon reflects the sharing of bicycles contrary to one aspect of ecological philosophy. Damaged shared bicycle can not be repaired in time, is a kind of garbage, and this garbage more and more, but also to the user to bring a very bad experience. But if at the beginning of the design, it is not easy to be damaged materials, or have a complete and timely repair mechanism, it will not produce so much garbage, to occupy the public places. For example, whether to set up a dedicated shared bicycle maintenance point, in the app will be able to find the nearby maintenance point, if the user opened to the damaged shared bicycle, the car will be implemented to repair point will be a certain online reward. In this way, it is not necessary to break the shared bicycle in the sidewalk on the space also affect the user experience, but also promptly deal with the scrapped garbage.

This is the point where the motorbike is better than the sharing of bicycles. Mobike is recognized as a good word of mouth to share the bike, rarely encountered Mo Bai bicycle damage to the situation, which shows that its selection of materials and design of the cycling have spent the mind, the beginning of the good quality is the late use experience of the responsibility, which is in line with the ecological concept. Therefore, the product design can not just have the Internet characteristics, this development will not long, but also in line with the ecological design concept in order to have tenacious vitality.

Millet Ecological Chain. Millet as a representative of the rapid rise of Internet companies, and put forward the concept of product ecology, advocate new domestic goods, concerned about the user experience, so as to establish brand self-confidence and reputation. Millet products have their own characteristics, not only reflected in the design above, but also reflected in their products can communicate with each other, forming a product ecosystem.

Take the millet out of the section that is beta beta millet speaker, as shown in Figure 7, it uses 360 degrees far field voice control, not only can provide massive online music, fiction comic, children's story, radio. Or artificial intelligence life assistant and intelligent equipment control center. Millet AI speakers currently controllable televisions, boxes, sweeping robots, rice cookers, air purifiers, electric fans, smart lights and other millet and ecological chain equipment. Even if not millet products, millet AI speakers can also be easily controlled by the rice home smart socket, plug panel, Aqara wall switch, air conditioning companion light product, as shown in Figure 8. 


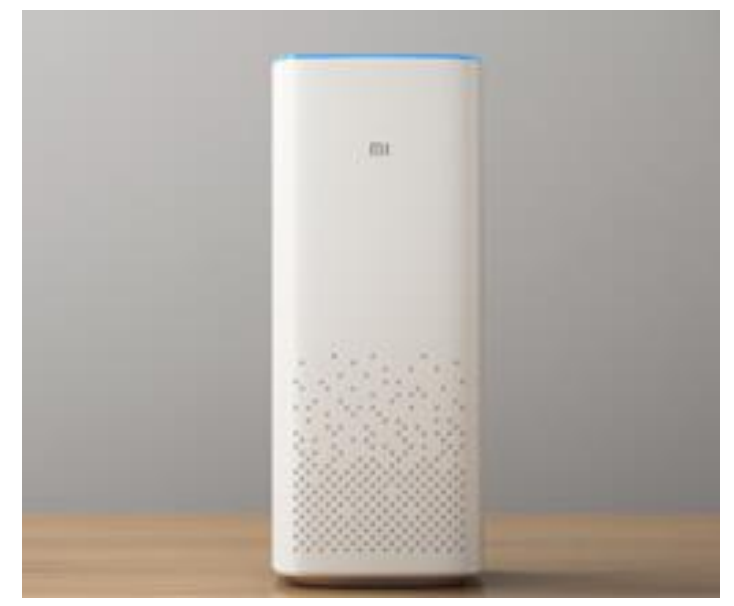

Figure 7. Millet AI speaker (picture from the network)

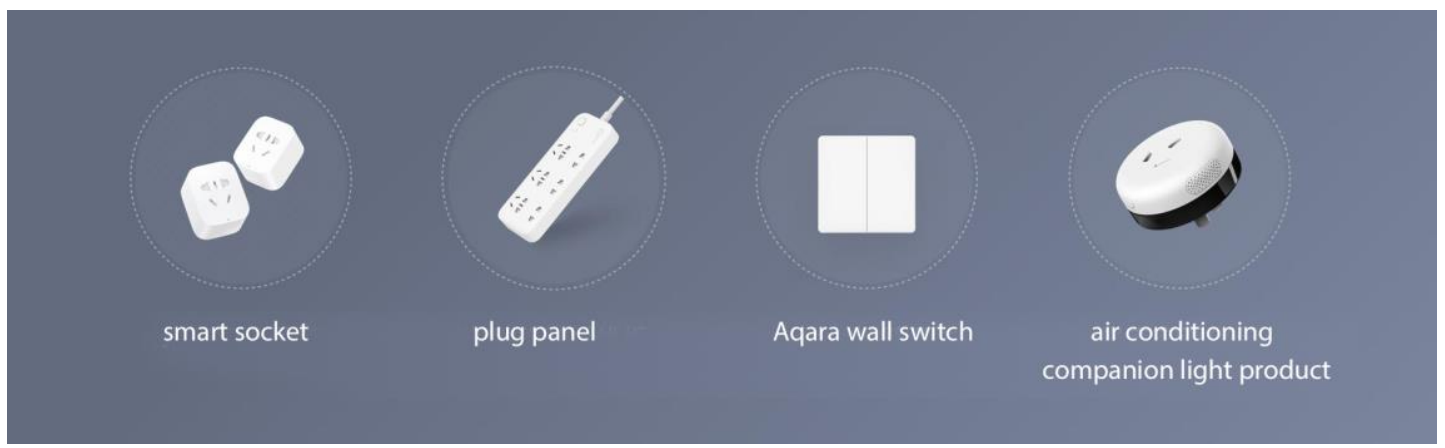

Figure 8. Millet smart accessories (picture from the network)

Millet products at the beginning of the design have taken into account its future in contact with other new products, that is, early on the set up an ecological concept, so that all of its products can be developed in this ecosystem is good, more importantly, Users bring a better, more convenient experience.

As mentioned above, although the shared bicycle has the Internet characteristics, but did not form a good ecological circle, the scrapping rate is too high, take up too much public space, the user experience is poor and so are not set in the early product design ecology result. (2) the country more than 400 maintenance points, to provide an hour fast repair phone. This is undoubtedly a better user experience to use, to extend the product life cycle, in line with ecological concepts.

\section{Conclusion and Prospect}

Through the data collection research and case analysis, we can find that product design to meet the functional needs on the basis of more emphasis on people-oriented, environment-friendly, pleasant, livable, sustainable products will be more market competitiveness, but also more representative of the future development trend.

The existing PI design has been unable to keep up with the pace of the Internet era, but it has not been a summary of the previous, with the Internet characteristics of the PI design concept, of course, is not enough, coupled with the concept of ecological guidance is the future development of PI design direction. It is expected that the future will be able to explore a more in line with the current design concept and future development trend of the new PI design concept, the initial Internet features, ecological concepts and extend the product life cycle into the points, but more comprehensive and more comprehensive new PI design elements, processes, methods need further study. 


\section{References}

[1] Ye Dehui. Internet era of product and service design trends [A]. Education Department of Higher Education Industrial Design Teaching Guidance Subcommittee, China Mechanical Engineering Society of Industrial Design Branch, China Machinery Industry Education Association of Industrial Design Discipline Teaching Committee .2016 National Industrial Design Education Seminar and International Industrial Design Summit Forum Proceedings [C]. Ministry of Education of Higher Education Industrial Design Teaching Guidance Subcommittee, China Mechanical Engineering Society of Industrial Design Branch, China Machinery Industry Education Association of Industrial Design Discipline Teaching Committee, 2016 : 4. (in Chinese)

[2] F.L. Song. Internet era under the product design [J]. Intelligent manufacturing, 2016, (04): 20-21. (in Chinese)

[3] H.M. Hao. Internet era of product design research [J]. Modern decoration (theory), 2015, (08): 132. (in Chinese)

[4] Y.Q. Yin. Based on the ecological concept of product energy saving design method [D]. Xi'an University of Engineering, 2011. (in Chinese)

[5] S.L. Guo, H.F. Zhou and X.S. Liu. Green design concept in the application of industrial products [J]. Shandong Industrial Technology, 2016, (18): 255. (in Chinese)

[6] X.F. Ge, J.H. Zhao. Product identification in product design [J]. Art and Design (Theory), 2008,04: 153-155. (in Chinese)

[7] X.L. Zhang. PI in the enterprise product development design application [D]. Zhejiang University of Technology, 2012.(in Chinese)

[8] Mozota B B. Design management using to build brand value and corporate innovation [M]. New York: All Worth Press, 2013.

[9] Z. Wang and J.H. Zhao. On the construction machinery brand modeling characteristics of innovation [J]. Decorative, 2013 (12): 98-99. (in Chinese)

[10] X.Y. Wang. Product image (PI) elements of the composition, evaluation and shaping research [J]. Commercial Research, 2000,08: 52-55. (in Chinese) 